JURNAL SEHAT MASADA VOLUME XIV NOMOR 1 Januari 2020 ISSN : 1979-2344

\title{
EFEKTIVITAS PEMBEKALAN MATERI KESEHATAN REPRODUKSI TENTANG BAHAYA PERNIKAHAN DINI UNTUK REMAJA PUTRI
}

\author{
Fardila Elba ${ }^{1}$, Merry, wijyaya ${ }^{2}$ \\ ${ }^{1,2}$ Departemen Ilmu Kesehatan Masyarakat, Fakultas Kedokteran, Universitas Padjadjaran \\ fardilaelba@yahoo.com \\ merry_wijaya0605@yahoo.com
}

\begin{abstract}
Early marriage is still a major concern for women's health in Indonesia. The lack of information on the dangers of early marriage make adolescents do not understand the consequences, so they took the decision to marry early without considering the risk. This study aims to find out the effectiveness of reproductive health material supply about the dangers of early marriage of girl adolescents' knowledge

Quantitative study one group pre-and post-test pre-experimental design, done in the Kalisari Village, Karawang Regency, in May 2018. The population consists of 316 girl adolescents. Sample a number of 101 people elected by proportionate stratified random sampling. Data source derived from primary data (questionnaire) and secondary data (book-keeping register of annual reports on the KUA). The data were analyzed using paired T-test and calculation of the effect size (ES). The results show that the pre-test score $(R=66.14, S D=15.38)$ increase to a post-test score $[R=76.36, S D=16.10, t$ $(101)=7.65, p=0000]$. The intervention has great effectiveness $(E S \geq 0.14)$ towards increased knowledge of girl adolescents about the dangers of early marriage $(E S=0.37)$. Reproductive health material supply about the dangers of early marriage is effective to increase the knowledge of girl adolescents.
\end{abstract}

Keyword : Adolescent, Early Marriage, Knowledge, Reproductive Health.

\begin{abstract}
ABSTRAK
Pernikahan dini masih menjadi perhatian utama bagi kesehatan wanita di Indonesia. Kurangnya informasi mengenai bahaya pernikahan dini membuat remaja tidak memahami konsekuensinya, sehingga mereka mengambil keputusan untuk menikah dini tanpa mempertimbangkan risikonya. Studi ini bertujuan untuk mengetahui efektivitas pembekalan materi kesehatan reproduksi tentang bahaya pernikahan dini terhadap pengetahuan remaja putri. Metode penelitian menggunakan studi kuantitatif dengan rancangan eksperimental semu dengan metode pre test-post test design, dilakukan di Desa Kalisari, Kabupaten Karawang, pada bulan Mei 2018. Populasi terdiri dari 316 remaja putri. Sampel sejumlah 101 orang dipilih secara proportionate stratified random sampling. Sumber data berasal dari data primer (kuesioner) dan data sekunder (buku register pencatatan laporan tahunan di KUA). Data dianalisis menggunakan paired T-test dan perhitungan effect size (ES). Hasil penelitian menunjukkan bahwa setelah intervensi terdapat peningkatan yang signifikan pada skor pengetahuan yaitu dari $(\mathrm{R}=66.14$, s.b $=15.38)$ menjadi $[\mathrm{R}=76.36$, $\mathrm{s} . \mathrm{b}=16.10, \mathrm{t}(101)=7.65, \mathrm{p}=0.000]$. Intervensi memiliki efektivitas yang besar $(E S \geq 0.14)$ terhadap peningkatan pengetahuan remaja putri tentang bahaya pernikahan dini $(\mathrm{ES}=0.37)$.

Pembekalan materi kesehatan reproduksi tentang bahaya pernikahan dini efektif untuk meningkatkan pengetahuan remaja putri.

Kata Kunci: remaja,pernikahan, Pendidikan, kesehatan reproduksi
\end{abstract}

Jurnal Penelitian Kesehatan STIKes Dharma Husada Bandung

14 


\section{PENDAHULUAN}

Masa remaja merupakan transisi antara periode anak menuju periode dewasa. Remaja memiliki emosi yang labil dan rasa keingintahuan yang besar, mereka selalu mencari tahu tentang hal-hal yang dianggap menarik, ingin bertindak seperti orang dewasa, dan lebih percaya dengan teman sebaya.(WHO, 2014) Oleh karena itu, untuk menghindari risiko yang berbahaya bagi remaja, diperlukan adanya pencerahan, perhatian, dan perlindungan yang khusus, agar remaja memahami cara memproteksi diri dari berbagai bahaya yang dapat merugikan masa depannya.

Hasil Survei Demografi dan Kesehatan Indonesia (SDKI) tahun 2012 didapatkan, remaja pada kelompok umur 15-19 tahun, 4,5 \% laki-laki dan $0,7 \%$ perempuan pernah melakukan seks pranikah dengan alasan $53,8 \%$ karena penasaran/ingin tahu, 23,6\% terjadi begitu saja, 2,6\% dipaksa pasangan, 1,8\% ingin menikah, dan $1,2 \%$ pengaruh teman.(InfoDATIN, 2012) Dampak dari perilaku seksual pranikah dapat mengakibatkan hamil luar nikah yang dapat berlajut dengan pernikahan dini. Selain itu, remaja pada usia tersebut belum memiliki keterampilan hidup (life skills) yang memadai, akibatnya terjadi Kekerasan Dalam Rumah Tangga (KDRT) yang mengakibatkan tingginya kasus perceraian.

Berdasarkan data BKKBN tahun 2016, terdapat $70 \%$ angka perceraian di Indonesia, salah satunya karena pernikahan dini.(BKKBN, 2016)

Menurut data SDKI tahun 2012 angka pernikahan dini di Indonesia sebesar 12,6\%.(Kesehatan, 2013) Faktor eksternal yang memengaruhi pernikahan dini antara lain yaitu sosial budaya, lingkungan, atau informasi dari sumber media yang tidak tepat, yang selanjutnya akan memengaruhi perubahan gaya hidup dan pola asuh orang tua, sehingga berpengaruh besar terhadap pengetahuan, sikap, dan perilaku remaja terkait kesehatan reproduksi.(Muzaini, 2014; Wartella, Rideout, Zupancic, BeaudoinRyan, \& Lauricella, 2015) Dampak pernikahan dini sangat mempengaruhi psikologis dan fisik remaja,(Ahmed, Khan, Khan, \& Noushad, 2014) terutama remaja putri, karena organ reproduksi belum tumbuh sempurna... Berbagai survei membuktikan, ibu di bawah usia 20 tahun sebagian besar mengalami anemia, serta sangat berisiko mengalami komplikasi persalinan seperti perdarahan, infeksi, abortus dan berisiko menambahan kasus kematian ibu. Bayi yang dikandung oleh ibu usia muda ( $<20$ tahun) berisiko mengalami Intra Uterin Grow Restriction (IUGR), partus prematurus, Bayi Berat Lahir Rendah (BBRL), aspiksia dan jika tidak ditangani dengan cepat dan tepat dapat terjadi kematian bayi. Ibu usia muda ( $<20$ tahun) masih senang main, kurang pengalaman dalam asuh anak, sehingga anak tidak dapat tumbuh dan berkembang secara optimal. 
Berdasarkan hasil studi pendahuluan di Desa Kalisari, masih banyak kasus pernikahan dini, bahkan terdapat remaja putri yang telah sering melakukan hubungan seksual dengan pasangannya yang berpenyakit menular seksual dan mengkonsumsi obat terlarang, remaja putri tersebut tidak berdaya dan tidak berupaya untuk meninggalkannya. Berdasarkan survei tersebut juga didapatkan bahwa remaja di Desa Kalisari masih memiliki pengetahuan yang rendah mengenai kesehatan reproduksi, sehingga pendidikan kesehatan reproduksi penting untuk diberikan.

Berdasarkan uraian tersebut, peneliti tertarik untuk melakukan penelitian tentang Efektivitas Pembekalan Materi Kesehatan Reproduksi tentang Bahaya Pernikahan Dini untuk Remaja Putri yang bekerjasama dengan KUA dalam penerapan globasisasi salah satu upaya yang dilakukan Kementerian Agama dengan menyelenggarakan kursus pra-nikah yang dilaksanakan di KUA di Kecamatan Talagasari sebagai Pilot Projek.

\section{METODE}

Penelitian ini merupakan penelitian kuantitatif dengan rancangan eksperimental semu dengan metode pre test-post test design.(Sopiyudin, 2011) Penelitian ini dilaksanakan di Desa Kalisari Kecamatan Talagasari Kabupaten Karawang. Waktu penelitian dilakukan pada bulan Mei 2018. Populasi terdiri dari 316 remaja putri di Desa
Kalisari. Pengambilan sampel berjumlah 101 orang dipilih dengan cara proportionate stratified random sampling yang dibagi berdasarkan tingkat RW, yaitu: RW 01 (8 orang), RW 02 (13), RW 03 (9), RW 04 (12), RW 05 (8), RW 06 (15), RW 07 (11), RW 08 (15), dan RW 09 (10). Protokol studi ini telah mendapatkan persetujuan etik dari Komisi Etik Penelitian Kesehatan Fakultas Kedokteran Universitas Padjadjaran Bandung (No: 1064/UN6.KEP/EC/2018).

Data yang digunakan pada penelitian ini adalah data primer dan data sekunder. Pengumpulan data primer diperoleh melalui kuesioner, sedangkan data sekunder melalui buku register pencatatan laporan tahunan di KUA wilayah penelitian.(Sopiyudin, 2011) Kuesioner untuk mengukur pengetahuan tentang bahaya pernikahan dini dirancang oleh peneliti yang menghasilkan 25 butir pertanyaan. Kuesioner tersebut telah diuji reliabilitasnya kepada 30 subjek yang mempunyai karakteristik yang sama dengan subjek penelitian, dimana didapatkan Cronbach's alpha 0.886 .

Pada penelitian ini, analisis yang dilakukan meliputi :

1) Analisis univariat untuk melihat gambaran karakteristik usia dan pendidikan responden.

2) Analisis bivariat untuk mengetahui perbedaan skor pengetahuan saat sebelum dan sesudah intervensi. Sebelum dianalisis, terlebih dahulu dilakukan uji normalitas 
dengan menggunakan uji Kolmogorovsmirnov karena besar sampel > 50, dan didapatkan hasil bahwa data terdistribusi normal ( $\mathrm{p}>0.05$ ). Oleh karena itu, analisis bivariat yang digunakan ialah Paired $T$ test.(Dahlan, 2014)

3) Analisis efektivitas intervensi untuk melihat sejauh mana kekuatan efek dari intervensi yang dilakukan. Adapun rumus yang sering digunakan untuk menghitung effect size pada Paired T-test ialah dengan Eta squared:

Eta squared $=\frac{t^{2}}{t^{2}+n-1}$

Keterangan:

$t$ : $t$-score

$n$ : Jumlah sampel

Nilai effect size berkisar antara 0-1. Untuk menginterpretasikan hasil kekuatan effect size pada uji Paired T-test dapat menggunakan acuan (dari Cohen, 1988):

$\geq 0.01 \quad$ : Efek yang kecil

$\geq 0.06 \quad$ : Efek yang sedang

$\geq 0.14 \quad$ : Efek yang besar(Pallant, 2005)

\section{HASIL DAN PEMBAHASAN}

\section{Perbedaan Pengetahuan Saat Sebelum dan Sesudah Intervensi}

Pada Tabel 1 menunjukkan bahwa terjadi peningkatan pengetahuan responden di Desa Kalisari setelah diberikan pembekalan materi kesehatan reproduksi tentang bahaya pernikahan dini, dimana rerata dan simpang baku pengetahuan sebelum intervensi adalah 66.14 (15.38), sedangkan setelah intervensi menjadi 76.36 (16.10). Selain itu, pada Tabel 1 juga menunjukkan bahwa nilai $\mathrm{p}<0.05$ dan IK tidak melewati 0 , sehingga secara statistik terdapat perbedaan pengetahuan yang signifikan sebelum dan setelah intervensi.

\section{Tabel 1 Perbedaan Pengetahuan Melalui Pembekalan Materi Kesehatan Reproduksi tentang Bahaya Pernikahan Dini di Desa Kalisari}

\begin{tabular}{|c|c|c|c|c|c|}
\hline Variabel & $\mathrm{N}$ & $\begin{array}{c}\text { Rerata } \\
\text { (Simpang } \\
\text { Baku) }\end{array}$ & $\begin{array}{c}\text { Selisih } \\
\text { (Simpang } \\
\text { Baku) }\end{array}$ & IK95\% & $\begin{array}{c}\text { Nilai } \\
p^{*}\end{array}$ \\
\hline \multicolumn{6}{|l|}{ Pengetahuan } \\
\hline Pre test & 101 & $\begin{array}{c}66.14 \\
(15.38)\end{array}$ & $\begin{array}{c}10.22 \\
(13.42)\end{array}$ & $\begin{array}{c}7.57- \\
12.87\end{array}$ & 0.000 \\
\hline Post test & 101 & $\begin{array}{c}76.36 \\
(16.10)\end{array}$ & & & \\
\hline
\end{tabular}

*Paired T-test

Menurut studi sebelumnya, skor $\leq 55$ termasuk ke dalam kategori pengetahuan kurang, skor 56-75 dikategorikan cukup, sedangkan skor 76-100 dikategorikan baik.(Amelia, Mohdari, \& Azizah, 2017) Oleh karena itu, pada studi ini, dapat dikatakan bahwa umumnya responden memiliki pengetahuan yang cukup saat sebelum diberikan intervensi. Hasil ini sejalan dengan beberapa studi sebelumnya yang menggambarkan bahwa sebagian besar remaja putri memiliki pengetahuan yang cukup mengenai bahaya pernikahan dini.(Amelia, et al., 2017; Setiawati, 2018; Wahyuni, Afandi, \& Widiawati, 2017) 
Hal tersebut dapat dipengaruhi oleh karakteristik responden yang terdapat pada Tabel 2, yaitu usia dan pendidikan, dimana sebanyak $65.3 \%$ responden merupakan siswi SMP.

\section{Tabel 2 Karakteristik Responden di Desa Kalisari}

\begin{tabular}{lccc}
\hline Karakteristik & $\begin{array}{c}\text { Jumlah } \\
(\mathrm{n})\end{array}$ & Median & $\begin{array}{c}\text { Minimum- } \\
\text { Maksimum }\end{array}$ \\
\hline Usia & 101 & 14 & $12-19$ \\
\hline Karakteristik & & $\begin{array}{c}\text { Jumlah } \\
(\mathrm{n})\end{array}$ & $\begin{array}{c}\text { Persentase } \\
(\%)\end{array}$ \\
\hline Pendidikan & & & \\
SD & & 13 & 12.9 \\
SMP & & 66 & 65.3 \\
SMA/SMK & & 22 & 21.8 \\
\hline
\end{tabular}

Berdasarkan teori, semakin bertambahnya usia dan semakin tingginya pendidikan maka semakin berkembang pula daya tangkap dan pola pikir seseorang, sehingga semakin mudah menerima informasi dan pengetahuan yang diperoleh semakin baik.(Budiman \& Riyanto, 2013; Sangging, Setyowati, \& Mardiyaningsih, 2014; Zain \& Zain, 2017) Beberapa studi sebelumnya menunjukkan bahwa tingkat pendidikan yang rendah berhubungan dengan kecenderungan dalam melakukan pernikahan dini.(Maliana, 2017; Sah et al., 2014; Sari \& Saragih, 2018; Wulanuari, Anggraini, \& Suparman, 2017; Yüksel-Kaptanoğlu \& Ergöçmen, 2014; Zain \& Zain, 2017) Seseorang yang pendidikannya rendah lebih berpeluang untuk menikah dini yaitu sebesar 0.463 kali dibandingkan dengan yang pendidikan tinggi.(Idawati, 2018) Hal tersebut disebabkan karena pola pikir yang sempit, sehingga dalam pengambilan keputusan tidak disertai dengan pertimbangan yang matang mengenai dampak dan akibat dari menikah dini.(Rahman, Syahadatina, Aprillisya, \& Afika, 2015; Sardi, 2016) Seseorang yang berpendidikan juga akan cenderung lebih sering mengakses media dan mampu mencari informasi tentang dampak negatif dari pernikahan dini. Dengan pengetahuan tersebut, ia akan mampu menolak upaya orang tuanya untuk menikahkannya diusia dini.(Adu Boahen \& Yamauchi, 2017)

\section{Efektivitas Intervensi}

Berdasarkan perhitungan effect size (ES) dengan Eta squared, pada Tabel 3 didapatkan hasil 0.37 yang berarti pembekalan materi kesehatan reproduksi tentang bahaya pernikahan dini memiliki efektivitas yang besar $(\mathrm{ES} \geq 0.14)$ terhadap peningkatan pengetahuan responden di Desa Kalisari.

\section{Tabel 3 Efektivitas Pembekalan Materi Kesehatan Reproduksi tentang Bahaya Pernikahan Dini di Desa Kalisari}

\begin{tabular}{cccc}
\hline Variabel & \multicolumn{3}{c}{ Desa Kalisari } \\
\cline { 2 - 4 } & $\mathrm{n}$ & $t$ score & Effect Size \\
\hline Pengetahuan & 101 & -7.65 & 0.37 \\
\hline
\end{tabular}

Hasil studi ini sejalan dengan penelitian sebelumnya yang juga dilakukan di Indonesia, yang menunjukkan bahwa pendidikan kesehatan berpengaruh signifikan terhadap peningkatan pengetahuan remaja $(p=0.016)$, dimana remaja yang diberikan pendidikan kesehatan memiliki 
pengetahuan 6 kali lebih baik tentang pernikahan dini dibandingkan dengan remaja yang tidak diberi pendidikan kesehatan.(Amelia, et al., 2017) Intervensi tersebut akan semakin efektif mengurangi pernikahan dini dan meningkatkan usia perkawinan apabila diberikan pada remaja muda (< 17 tahun).(Amin, Saha, \& Ahmed, 2018)

Pada studi ini, pembekalan materi kesehatan reproduksi diberikan melalui metode partisipatif. Metode ini menuntut adanya partisipasi remaja, dimana remaja tidak hanya menerima informasi satu arah saja akan tetapi dilibatkan secara proaktif dalam diskusi yang bersifat terbuka, sehingga setiap remaja memiliki hak yang sama untuk bicara ataupun didengar.(Muchtar, 2016; Taukhit, 2014) Beberapa studi sebelumnya juga menunjukkan bahwa metode pendidikan partisipatif lebih efektif dalam meningkatkan pengetahuan bila dibandingkan dengan metode ceramah.(Sembiring, 2015; Taukhit, 2014) Pada studi ini, pendidikan partisipatif diberikan dengan media power point. Penelitian sebelumnya menunjukkan bahwa pendidikan kesehatan dengan media powerpoint berpengaruh secara signifikan $(\mathrm{p}<0.001)$ terhadap peningkatan pengetahuan remaja,(Helmiwati, 2016; Mariani \& Lisnawati, 2018) bahkan lebih efektif bila dibandingkan dengan media leaflet.(Helmiwati, 2016) Menurut teori, pengetahuan diperoleh setelah seseorang melakukan pengindraan terhadap suatu objek, dimana semakin banyak indra yang dilibatkan maka semakin baik pengetahuan yang diperoleh.(Notoatmodjo, 2012)

Tingkat pengetahuan seseorang akan berpengaruh terhadap kematangan psikososial dan kemampuan berpikirnya.(Maliana, 2017; Sari \& Saragih, 2018) Semakin tinggi tingkat pengetahuan maka semakin mudah untuk berpikir rasional, menguraikan dan menyikapi masalah, serta membuat keputusan.(Sangging, et al., 2014) Pada dasarnya remaja perlu dibekali dengan informasi mengenai bahaya pernikahan dini supaya mereka mampu memahami konsekuensinya, sehingga mereka tidak sematamata mengambil keputusan untuk melakukan pernikahan dini tanpa mengetahui risikonya.(Setiawati, 2018) Menunda usia pernikahan juga dapat meningkatkan pemberdayaan kesehatan wanita, dimana dengan begitu maka kesehatan anak pun akan turut meningkat dikarenakan berkurangnya kehamilan diusia dini.(Delprato \& Akyeampong, 2017)

\section{KESIMPULAN}

1) Pengetahuan remaja putri di Desa Kalisari tentang bahaya pernikahan dini pada umumnya termasuk ke dalam kategori cukup.

2) Terdapat peningkatan pada skor pengetahuan saat sebelum dan sesudah diberikan pembekalan materi kesehatan reproduksi tentang bahaya pernikahan dini, dimana intervensi tersebut memiliki efek 
yang besar terhadap peningkatan

pengetahuan remaja putri.

\section{DAFTAR PUSTAKA}

Adu Boahen, E., \& Yamauchi, C. 2017. The effect of female education on adolescent fertility and early marriage: evidence from free compulsory universal basic education in Ghana. Journal of African Economies, 27(2), 227-248.

Ahmed, S., Khan, A., Khan, S., \& Noushad, S. 2014. Early marriage; a root of current physiological and psychosocial health burdens. International Journal of Endorsing Health Science Research, 2(1), 50-53.

Amelia, R., Mohdari, M., \& Azizah, A. 2017. Pengaruh penyuluhan terhadap pengetahuan remaja tentang pernikahan dini di kelas VIII di SMP Negeri 4 Banjarmasin. Dinamika Kesehatan Jurnal Kebidanan Dan Keperawatan, 8(1), 64-77.

Amin, S., Saha, J., \& Ahmed, J. 2018. Skillsbuilding programs to reduce child marriage in Bangladesh: a randomized controlled trial. Journal of Adolescent Health, 63(3), 293-300.

BKKBN. 2016. Kajian profil penduduk remaja (10-24 tahun): angka perceraian remaja. Jakarta: Policy Brief Puslitbang kependudukan-BKKBN.

Budiman, \& Riyanto, A. 2013. Kapita selekta kuesioner: Pengetahuan dan sikap dalam penelitian kesehatan. Jakarta: Salemba Medika.

Dahlan, M. S. 2014. Statistik untuk kedokteran dan kesehatan: deskriptif, bivariat, dan multivariat, dilengkapi aplikasi menggunakan SPSS (6 ${ }^{\text {th }}$ ed.). Jakarta: Epidemiologi Indonesia.

Delprato, M., \& Akyeampong, K. 2017. The effect of early marriage timing on women's and children's health in SubSaharan Africa and Southwest Asia. Annals of global health, 83(3-4), 557-567.
Helmiwati. 2016. Pengaruh penyuluhan metode ceramah dengan media leaflet dan media powerpoint terhadap pengetahuan dan sikap tentang pencegahan penyalahgunaan NAPZA pada siswa SMK Fathih Azahra Medan tahun 2016. Univestitas Sumatera Utara, Medan.

Idawati, I. 2018. Determinan Pernikahan Dini pada Satu Kecamatan di Kabupaten Lampung Selatan. Jurnal Keperawatan, 13(1), 132-141.

InfoDATIN. 2012. Situsi kesehatan reproduksi remaja 29 Juni dalam rangka hari keluarga nasional. Jakarta: Pusat data dan informasi kementerian kesehatan RI.

Kesehatan, K. (2013). Survei Demografi dan Kesehatan Indonesia 2012 Retrieved 30 Januari, 2017.

Maliana, A. 2017. Hubungan antara tingkat pendidikan perempuan dengan kejadian pernikahan usia dini di KUA wilayah kerja Kecamatan Purbolinggo. Jurnal Kesehatan Akbid Wira Buana, 1(1), 4246.

Mariani, N. N., \& Lisnawati. 2018. Pendidikan kesehatan berbasis multimedia berpengaruh terhadap pengetahuan tentang kesehatan reproduksi siswa. Care: Jurnal Ilmiah Ilmu Kesehatan, 6(3), 210218.

Muchtar, K. 2016. Penerapan komunikasi partisipatif pada pembangunan di Indonesia. Jurnal Makna, 1(1), 20-32.

Muzaini. 2014. Perkembangan teknologi dan perilaku menyimpang dalam masyarakat modern. Jurnal Pembangunan Pendidikan: Fondasi dan Aplikasi, 2(1), 48-58.

Notoatmodjo, S. 2012. Promosi kesehatan dan perilaku kesehatan (2 ${ }^{\text {nd }}$ ed.). Jakarta: Rineka Cipta.

Pallant, J. 2005. SPSS survival manual: step by step guide to data analysis using SPSS for windows (version 12) $\left(2^{\text {nd }} e d.\right)$. Crows Nest NSW: Allen \& Unwin.

Rahman, F., Syahadatina, M., Aprillisya, R., \& Afika, H. D. 2015. Kajian budaya remaja pelaku pernikahan dini di Kota Banjarbaru Kalimantan Selatan. Media 
Kesehatan Masyarakat Indonesia, 11(2), 108-117.

Sah, R., Gaurav, K., Baral, D., Subedi, L., Jha, N., \& Pokharel, P. 2014. Factors affecting early age marriage in Dhankuta Municipality, Nepal. Nepal Journal of Medical Sciences, 3(1), 26-30.

Sangging, N. K. M. A., Setyowati, H., \& Mardiyaningsih, E. 2014. Hubungan pengetahuan tentang menstruasi dengan kecemasan terhadap ketidakteraturan siklus menstruasi pada siswi kelas VIII DI SMP Negeri 1 Bergas. The Soedirman Journal of Nursing, 9(2), 94-102.

Sardi, B. 2016. Faktor-faktor pendorong pernikahan dini dan dampaknya di Desa Mahak Baru Kecamatan Sungai Boh Kabupaten Malinau. Ejournal SosiatriSosiologi, 4(3), 194-207.

Sari, D. M., \& Saragih, G. N. 2018. Faktorfaktor yang berhubungan dengan pernikahan dini pada wanita di Desa Serbananti Kecamatan Sipispis Kabupaten Serdang Bedagai. Jurnal Kesehatan Almuslim, 4(7), 1-9.

Sembiring, R. N. S. 2015. Efektifitas metode diskusi dan metode ceramah dalam meningkatkan pengetahuan dan sikap remaja tentang HIV/AIDS di SMPN 10 Kota Pematangsiantar tahun 2015. Universitas Sumatera Utara, Medan.

Setiawati, E. 2018. Hubungan pengetahuan remaja tentang resiko pernikahan dini dengan keinginan melakukan pernikahan dini. Jurnal Ilmiah Kesehatan Ar-Rum Salatiga, 2(2), 47-53.

Sopiyudin, D. 2011. Statistik untuk kedokteran dasar deskriptif, bivariat, dan multivariat: PT Salemba.

Taukhit. 2014. Pengembangan edukasi kesehatan reproduksi dan seksualitas remaja dengan metode game kognitif proaktif. Jurnal Studi Pemuda, 3(2), 123131.

Wahyuni, S., Afandi, A., \& Widiawati, S. A. 2017. Efektivitas Pusat Informasi dan Konseling Kesehatan Reproduksi Remaja (PIK-KRR) untuk mencegah terjadinya pernikahan dini bagi remaja. Paper presented at the Seminar Nasional Kesehatan Reproduksi Menuju Generasi Emas.

Wartella, E., Rideout, V., Zupancic, H., Beaudoin-Ryan, L., \& Lauricella, A. 2015. Center on media and human development, school of communication, Northwestern University. Teens, health, and technology: a national survey.

WHO. 2014. Health for the world's adolescents: a second chance in the second decade: World Health Organization.

Wulanuari, K. A., Anggraini, A. N., \& Suparman, S. 2017. Faktor-Faktor yang Berhubungan dengan Pernikahan Dini pada Wanita. Jurnal Ners dan Kebidanan Indonesia, 5(1), 68-75.

Yüksel-Kaptanoğlu, İ., \& Ergöçmen, B. A. 2014. Early marriage: trends in Turkey, 1978-2008. Journal of Family Issues, 35(12), 1707-1724.

Zain, M. F., \& Zain, I. M. 2017. Analisis berbasis cluster tentang faktor-faktor yang mempengaruhi perkawinan di bawah umur di Kabupaten Kediri. Swara Bhumi, 5(IV), 14-21. 